\title{
BMJ Open Losing ground at the wrong time: trends in self-reported influenza vaccination uptake in Switzerland, Swiss Health Survey 2007-2017
}

\author{
Kathrin Zürcher (D) , ${ }^{1}$ Marcel Zwahlen (D) , ${ }^{1}$ Claudia Berlin (D) , \\ Matthias Egger (D) , 1,2 Lukas Fenner (D) ${ }^{1,3}$
}

To cite: Zürcher K, Zwahlen M, Berlin C, et al. Losing ground at the wrong time: trends in self-reported influenza vaccination uptake in Switzerland, Swiss Health Survey 2007-2017. BMJ Open 2021;11:e041354. doi:10.1136/ bmjopen-2020-041354

- Prepublication history and additional materials for this paper is available online. To view these files, please visit the journal online (http://dx.doi org/10.1136/bmjopen-2020041354).

Received 05 June 2020 Revised 15 October 2020 Accepted 22 December 2020

Check for updates

(c) Author(s) (or their employer(s)) 2021. Re-use permitted under CC BY-NC. No commercial re-use. See rights and permissions. Published by BMJ.

${ }^{1}$ Institute of Social \& Preventive Medicine, University of Bern, Bern, Switzerland

${ }^{2}$ Population Health Sciences, Bristol Medical School, University of Bristol, BristolUK

${ }^{3}$ Kanton Solothurn

Gesundheitsamt, Solothurn, Switzerland

Correspondence to

Dr Lukas Fenner;

lukas.fenner@ispm.unibe.ch

\section{ABSTRACT}

Objectives We studied time trends in seasonal influenza vaccination and associations with socioeconomic and health-related determinants in Switzerland, overall and in people aged $\geq 65$ years.

Design Three cross-sectional surveys.

Participants Individuals who participated in the Swiss Health Surveys 2007, 2012 and 2017. We calculated the proportion reporting influenza vaccination in the last 12 months, and performed multivariable logistic regression analyses.

Results We included 51582 individuals in this analysis. The median age was 49 years (IQR 25-64), and 27518 were women (53.3\%). The proportion of reporting a history of influenza vaccination overall was $31.9 \%(95 \% \mathrm{Cl} 31.4$ to 32.4 ); and dropped from $34.5 \%$ in 2007 to $28.8 \%$ in 2017. The uptake of vaccination within the past 12 months was 16\% in 2007 and similar in 2012 and 2017 (around $14 \%$ ). In people with chronic disease, uptake dropped from $43.8 \%$ in 2007 to $37.1 \%$ in 2012 and to $31.6 \%$ in 2017 $(p<0.001)$. In people aged $\geq 65$ years, uptake dropped from $47.8 \%$ in 2007 to $38.5 \%$ in 2012 to $36.2 \%$ in 2017 $(p<0.001)$. In logistic regression, self-reported vaccination coverage decreased in the 65-75 years old (adjusted OR (aOR) $0.56,95 \% \mathrm{Cl} 0.48$ to 0.66 between 2007 and 2012; aOR $0.89,95 \% \mathrm{Cl} 0.77$ to 1.03 between 2012 and 2017). Uptake was positively associated with the $\geq 65$ age group, living in French-speaking and urban areas, history of smoking, bad self-reported health status, private/ semiprivate health insurance, having a medical profession and having any underlying chronic disease.

Conclusion Influenza vaccination coverage was low in older and chronically ill persons. Significant efforts are required in preparing for the influenza season 2020/2021 to reduce the double burden of COVID-19 and seasonal influenza. These efforts should include campaigns but also novel approaches using social media.

\section{INTRODUCTION}

Seasonal influenza is pandemic, and a challenge for surveillance, control and treatment. ${ }^{1}$ Worldwide, it causes 3-5 million cases of severe illness each year and kills 250000-500000 people, ${ }^{2}$ particularly infants, the elderly and the chronically ill. In Switzerland, influenza
Strengths and limitations of this study

- The Swiss Health Survey is a nationwide, representative survey that is repeated every 5 years using the same sampling methodology.

- Data analysis of the Swiss Health Survey 2007, 2012 and 2017 focussing on influenza vaccine uptake overall and in the age group $\geq 65$ years in Switzerland.

- We calculated per cent of people reporting having been vaccinated, analysed time trends and associations between vaccination status and sociodemographic and health-related factors.

- The analyses were weighted and adjusted for a range of potential confounders, which did not substantially change the results.

- Influenza vaccination status is self-reported in the Swiss Health Survey and the reliability of the data is not ascertained.

is responsible for 111000-331000 medical consultations yearly and 1000-5000 hospitalisations. ${ }^{3}$ The current COVID-19 pandemic shows the impact of respiratory viruses on the burden of infectious diseases and the importance of vaccines in the control of viral respiratory diseases. ${ }^{45}$

In 2003, the World Health Assembly adopted a resolution urging member states to reach a target for uptake of influenza vaccines of $75 \%$ among people at high risk by $2010 .^{6}$ The Federal Office of Public Health in Switzerland has vaccine recommendations in place since 2007, which target mainly elderly people, but also those with chronic illnesses (including children older than 6 months), premature infants, pregnant women, residents of long-term healthcare facilities and those are in regular contact with vulnerable populations. $^{\text {? }}$

We earlier analysed the data from the Swiss Health Survey 2007 and 2012 and showed that overall influenza vaccine uptake in 
Switzerland decreased from 2007 to $2012 .^{8}$ To examine recent trends and associations of sociodemographic characteristics and health-related factors with influenza vaccination practices in Switzerland, we analysed the data from the most recent nationally representative health survey, in 2017, and compared the results with those from 2012 and 2007.

\section{MATERIAL AND METHODS Survey sample}

The cross-sectional Swiss Health Survey has been conducted every 5 years since 1992 by the Swiss Federal Statistical Office (SFSO). The survey is a multistage probability sample drawn from all residents not living in institutions in Switzerland. ${ }^{8}$ Conducted between January and December of the year, the survey collects data using computer-assisted telephone interviews and selfcompleted questionnaires.

We compared the data set from 2017 with the data from 2012 and 2007 and only used survey data from the written forms. We excluded the telephone interviews because they were shorter and did not include all the questions. We included a total of 51582 people who responded to a written questionnaire; 14393 responded in 2007, 18357 in 2012 and 18632 in 2017.

\section{Data collection and definitions}

From all three surveys, we extracted data on influenza vaccination within the past 12 months. ${ }^{9}$

The questionnaire collected demographic and socioeconomic as well as health-related information (table 1) on chronic diseases such as diabetes, cancer, lung, cerebrovascular and cardiovascular disease. The basic health insurance is mandatory in Switzerland and provides cover for illness, maternity, and accidents, offering the same range of services to all insured people. ${ }^{10}$ The respondents' health insurance plan regarding coverage in case of hospitalisation (private, semiprivate, or general ward), free choice of physicians and coverage of complementary medicine (including acupuncture, traditional Chinese medicine, homoeopathy, and osteopathy) in the past 12 months was recorded as well.

Pregnancy was recorded as current pregnancy among women 15-49years old. Current chronic lung diseases included asthma, chronic bronchitis and emphysema. Diabetes was defined by the use of any diabetic drug, cardiovascular disease by the use of any heart medication, and all other chronic diseases were recorded as selfreported. We defined any chronic disease as the presence of at least one of the mentioned diseases. Healthcare workers were defined as individuals reporting profession in the healthcare system.

Cantons are the administrative subdivisions of Switzerland (see figure 1).

\section{Statistical analysis}

For each of the three survey years we calculated the proportions (overall and $\geq 65$ years) that reported having been vaccinated within the last 12 months. We estimated associations between vaccination status and sociodemographic and health-related factors. We included an interaction term with the year of survey and the variable of interest in multivariable logistic regression models. We used the SFSO's survey weights and reported all proportions and unadjusted and adjusted OR (aOR) with the corresponding 95\% CIs derived from robust SE calculations (table 2). All analyses were performed in Stata (V.15.1).

We visualised changes in the frequency of vaccination uptake, and geographical distributions of the population that reported vaccination for influenza at the cantonal level using ArcGIS V.10.5 (Redlands, California, USA).

\section{RESULTS}

\section{Trends of influenza vaccinations over time}

The proportion of survey participants reporting a history of influenza vaccination overall was $31.9 \%$ (95\% CI 31.4 to 32.4 ), having dropped from $34.5 \%$ in 2007 to $28.8 \%$ in 2017 . The proportion reporting vaccination within the past 12 months was $16.4 \%$ (95\% CI 15.6 to 17.2) in 2007, dropped to $14.1 \%$ (95\% CI 13.5 to 14.8 ) in 2012 , and remained at this level in 2017 (14.4\%, 95\% CI 13.8 to 15.0, $\mathrm{p}<0.001$, table 1$)$. Among those $\geq 65$ years old, the principal target population of the Swiss recommendations, ${ }^{7}$ vaccination in the past 12 months dropped from $47.8 \%$ (95\% CI 45.7 to 49.9 ) in 2007 to $38.5 \%$ (95\% CI 36.6 to 40.5 ) in 2012, and $36.2 \%$ (95\% CI 34.6 to 37.9) in 2017 $(\mathrm{p}<0.001)$. For those with any chronic disease, another at-risk population, the frequency of influenza vaccination dropped from $43.8 \%$ (95\% CI 40.9 to 46.8) in 2007 to $37.1 \%$ (95\% CI 34.6 to 39.7 ) in 2012, and further to $31.6 \%$ (95\% CI 29.7 to 33.6$)$ in 2017. Similarly, a decrease in vaccine uptake was seen in people with poor self-reported health status $(39.4 \%, 33.1 \%$ and $27.0 \%$, figure 2$)$.

From 2007 to 2012 the self-reported influenza vaccination in the last 12 months decreased in age group 15-19 years (aOR $0.51,95 \%$ CI 0.27 to 0.99 ) but increased from 2012 to 2017 in the younger age groups (eg, aOR $1.59,95 \%$ CI 0.92 to 2.74 in the $15-19$ years age group; aOR 1.19. 96\% CI 0.84 to 1.69 in the 20-29 years age group, figure 2 and table 2 ). In contrast, it decreased in the 65-75 years old between 2007 and 2017 (aOR 0.56, $95 \%$ CI 0.48 to 0.66 for 2007-2012; aOR 0.89 , $95 \%$ CI 0.77 to 1.03 for $2012-2017$, table 2 ). The $p$ value from the test for an interaction between period and age group was 0.01 for 2007-2012 and 0.051 for 2012-2017. In pregnant women, an increase of influenza vaccination was observed between 2007 and 2012 (aOR 4.43, 95\% CI 0.96 to 20.42, $\mathrm{p}=0.02$ ), with no further increase between 2012 and 2017 (aOR $0.94,95 \%$ CI 0.36 to $2.47, \mathrm{p}=0.45$ ). The temporal trends over the period 2007-2012 and 2012-2017 were not associated with age, language region, urban/rural setting, citizenship, any chronic disease, smoking status, use of complementary medicine or type of hospital stay insurance $(p>0.05$, table 2$)$. 


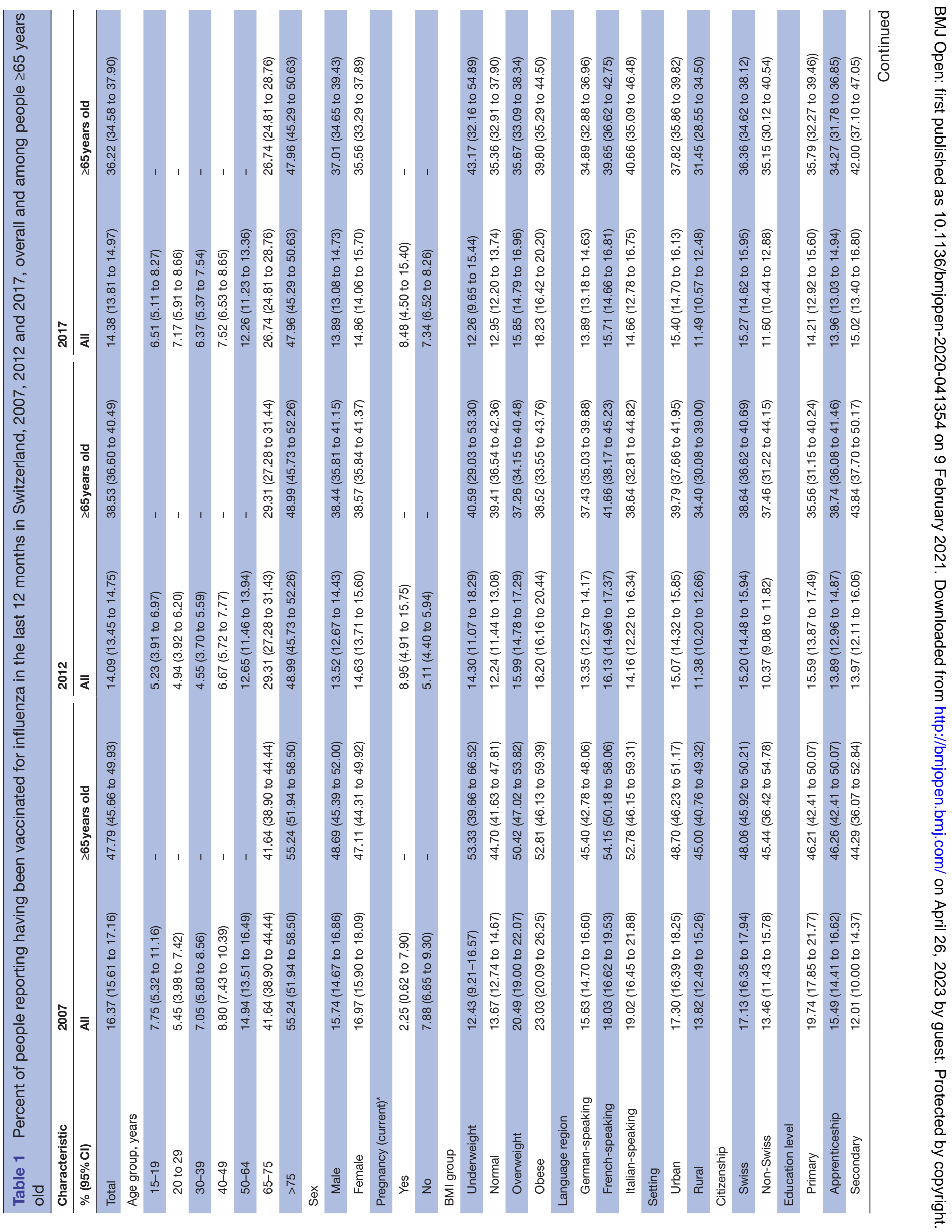




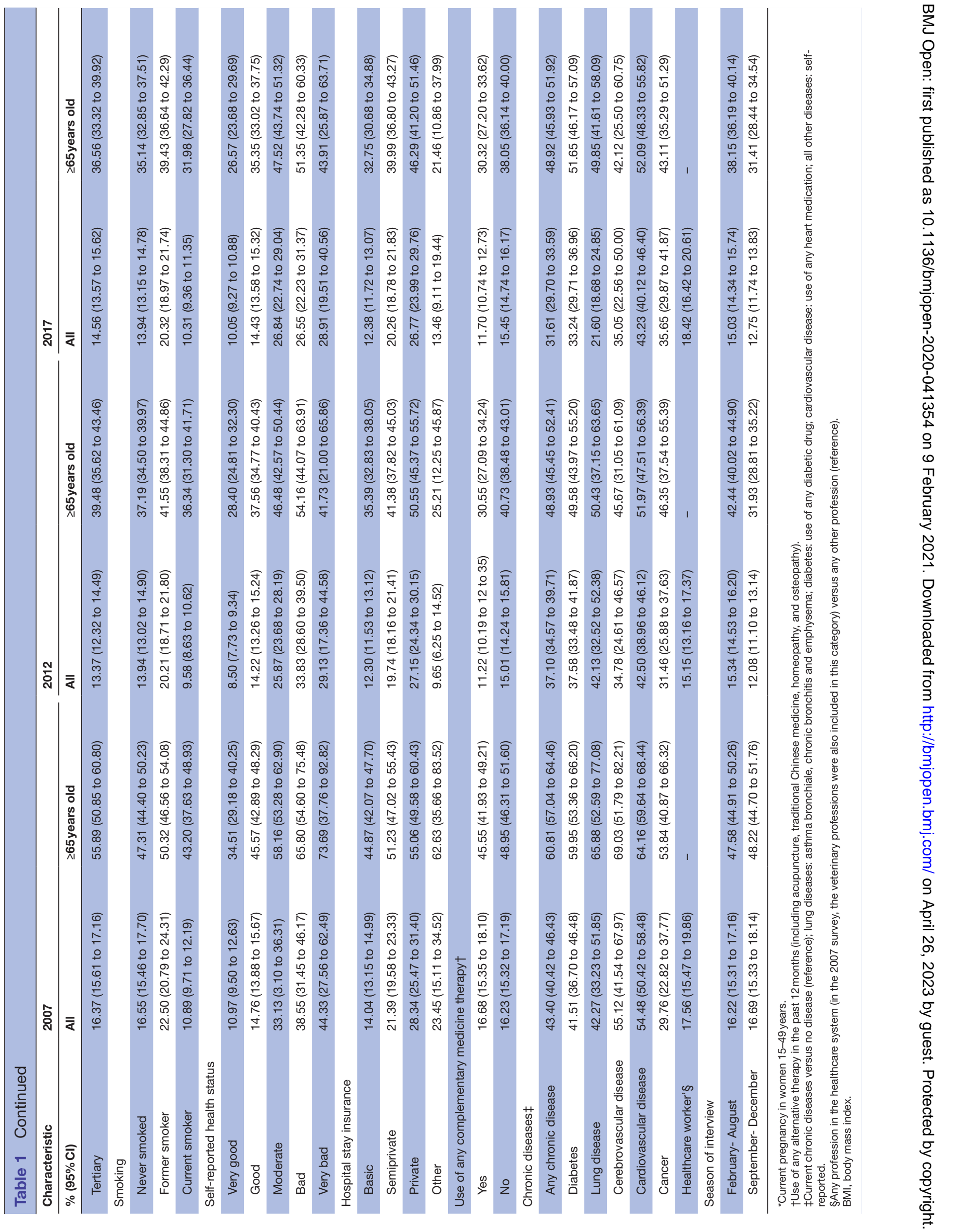



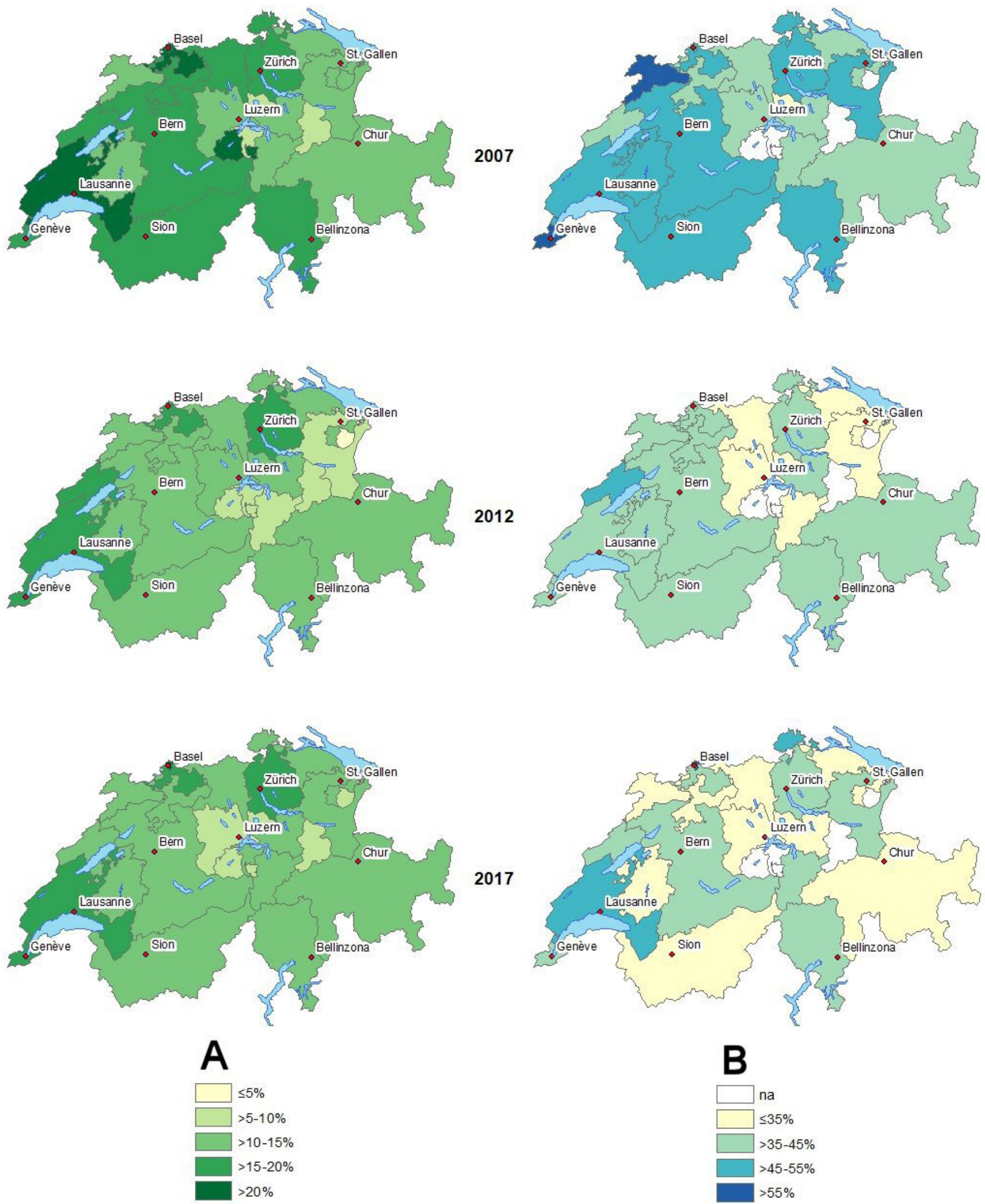

Figure 1 Geographical distribution (by canton) of people reporting influenza vaccination in the last 12 months in Switzerland, 2007 to 2017. (A) Overall; (B) people aged $\geq 65$ years. na, not applicable (no. of respondents $<100$ ). 


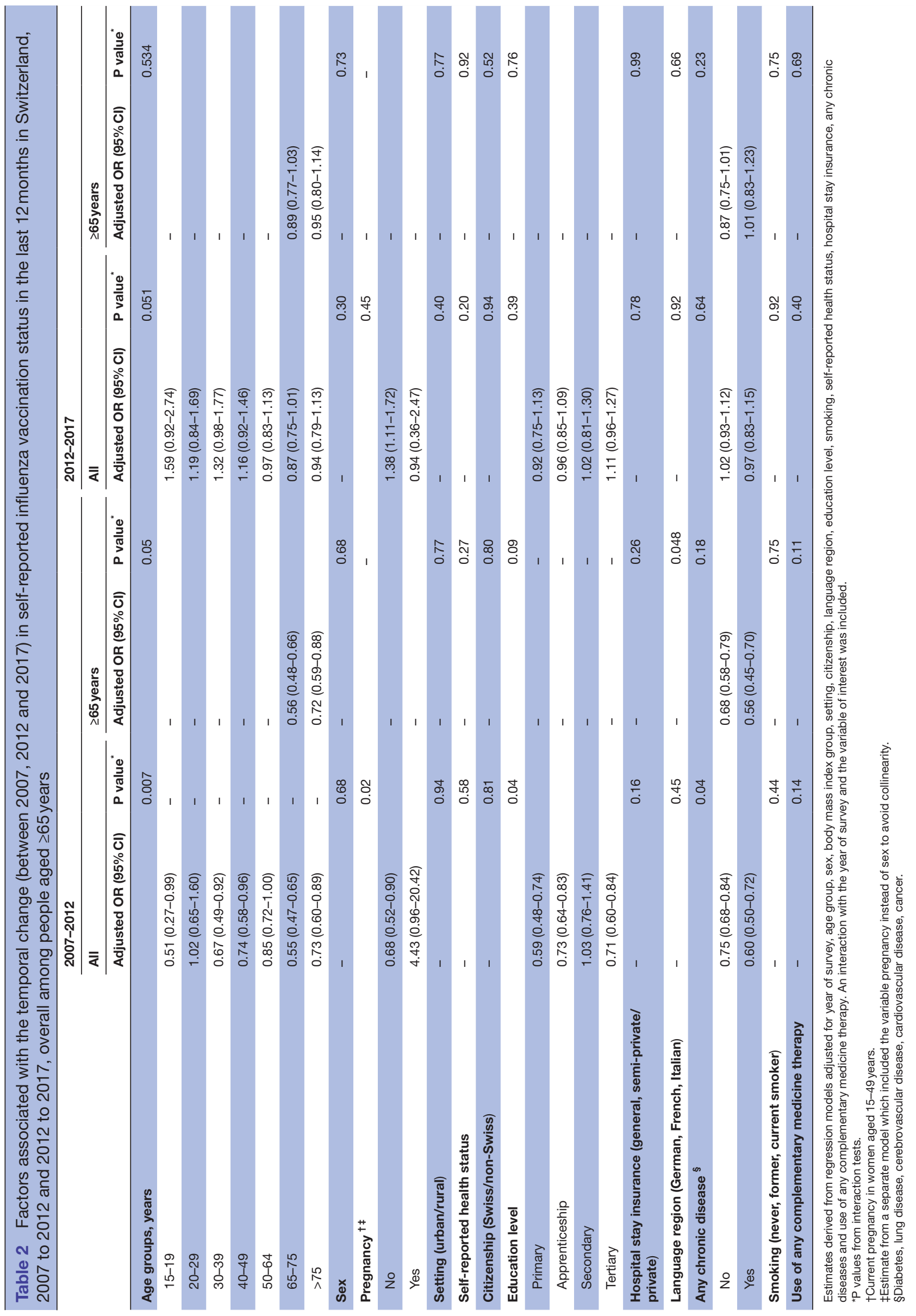




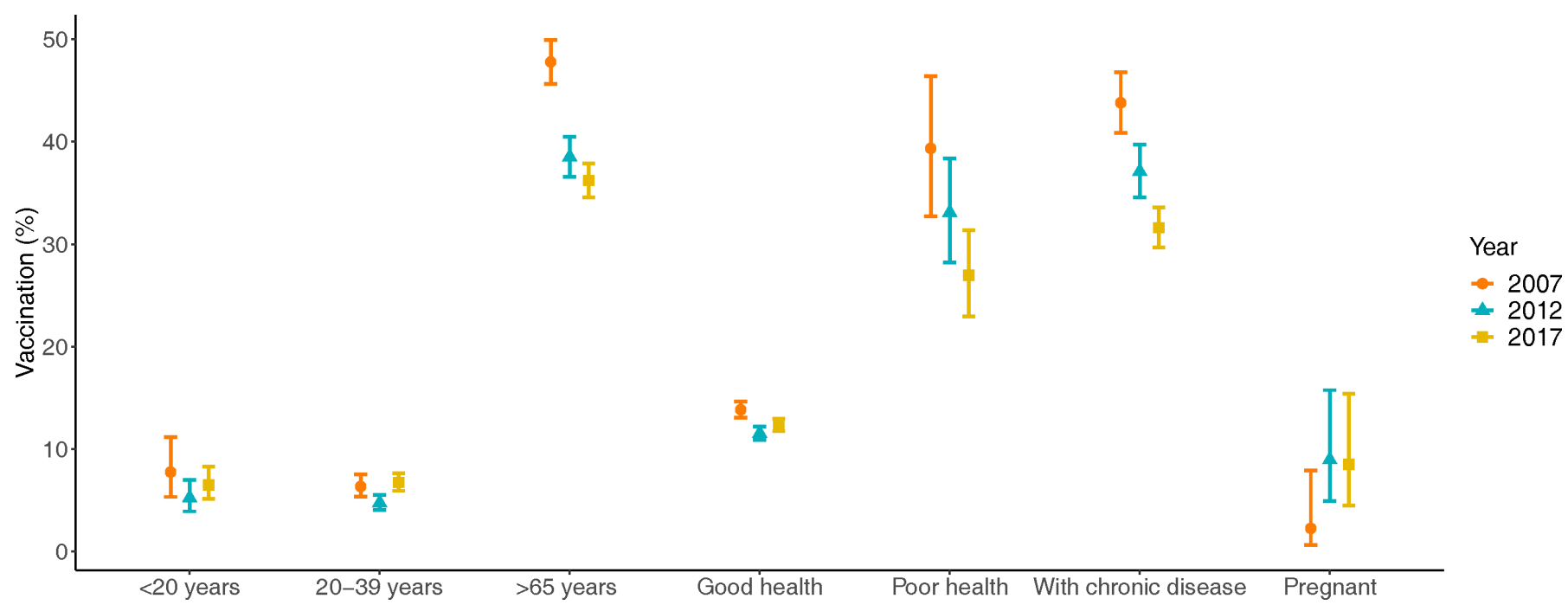

Figure 2 Temporal trends of selected groups of people reporting influenza vaccination in the last 12 months in Switzerland, comparing 2007 to 2017. Percent of people reporting having been vaccinated and the 95\% Cls are presented. Good health: self-reported health status good and very good; poor health: self-reported health status bad and very bad; with chronic disease: any chronic illness.

\section{Influenza vaccination status in different population groups}

In all three surveys, self-reported influenza vaccination in the last 12 months was highest in the age group $\geq 65$ years, and also higher in urban settings, among Swiss citizens, former smokers and in persons with supplemental health insurance (table 1). In all three surveys, the proportion of self-reported influenza vaccination was higher in the French-speaking and Italian-speaking region compared with the German region. Persons with chronic diseases were more frequently vaccinated for influenza, with uptake ranging from around $20 \%$ to $57 \%$ depending on age group and type of chronic disease. A lower proportion of self-reported vaccination was observed in ages 15 years to 50 years (range $4 \%-9 \%$ ), current smokers, and person who reported their health status as very good. The regional differences in the vaccination status in the last 12 months in the overall population and the $\geq 65$ age group are shown in figure $1 \mathrm{~A}, \mathrm{~B}$.

\section{Individual and health system factors associated with the influenza vaccination status}

In all three surveys, influenza vaccination in the last 12 months was positively associated with age 65 years or older, living in French-speaking and urban areas, having a tertiary education, history of smoking, bad self-reported health status, private/semiprivate hospital stay insurance, being a healthcare worker and having any underlying chronic disease. Use of any complementary medicine therapy was negatively associated with influenza vaccination (aOR $0.72,95 \%$ CI 0.67 to 0.80 ). We found no association with sex, body mass index or non-Swiss citizenship (table 3). Similar findings were observed when analysing only participants' $\geq 65$ years old. Online supplemental table 1 shows unadjusted and aORs of the associations between self-reported vaccination for influenza in the last 12 months and sociodemographic characteristics and health-related factors.

\section{DISCUSSION}

Progress toward the WHO target of $75 \%$ vaccination coverage among high-risk groups has not only stalled in Switzerland, some of the gains made in earlier years were lost by 2017. Of particular concern is that the selfreported seasonal influenza vaccination rate among elderly persons declined from $47.8 \%$ in 2007 to $38.5 \%$ in 2012 , and declined further to $36.2 \%$ in 2017 . People at risk due to underlying chronic diseases reported coverage of influenza vaccination of $31.6 \%$ in 2017 . Overall, after declining from $16.4 \%$ in 2007 to $14.1 \%$ in 2012, coverage in Switzerland was, with $14.4 \%$, similar in 2017.

A decline in influenza vaccine coverage in recent years has been observed in other European countries. In the European Region of WHO, vaccine uptake in older people ranged from $0.03 \%$ to $76.3 \%$ over seven seasons (2008/2009-2014/2015). The median was $34.4 \%$. In 2014/2015, only Scotland reached the WHO and European Council goal with an uptake of $75 \%$. Among countries providing data for seasons 2008/2009 and 2014/2015, over half reported a drop in vaccination coverage among older people. ${ }^{11}$ Among people with chronic diseases, coverage in the European Region ranged from $0.3 \%$ in Kyrgyzstan to $86.8 \%$ in Georgia in 2014/2015. ${ }^{11}$

From a historical perspective, vaccines have substantially reduced the burden for infectious disease (eg, polio, measles, mumps and rubella) or have been eradicated (small pox) ${ }^{12}$ Vaccine safety have always been a concern. For example, measles vaccine was falsely linked to autism in the 1990s, which led to a dramatically drop in vaccine coverage in the UK and other countries. Misleading 
Table 3 Associations of having been vaccinated for influenza in the last 12 months with sociodemographic characteristics and health-related factors (as compared with no vaccination) in Switzerland, 2007 to 2017, overall and among people $\geq 65$ years old

\begin{tabular}{|c|c|c|c|c|}
\hline \multirow[b]{2}{*}{ Characteristic } & \multicolumn{2}{|l|}{ All } & \multicolumn{2}{|l|}{$\geq 65$ years old } \\
\hline & Adjusted OR (95\% Cl) & $P$ value & Adjusted OR $(95 \% \mathrm{Cl})$ & $P$ value \\
\hline Year of survey & & $<0.001$ & & $<0.001$ \\
\hline 2007 & 1 & & 1 & \\
\hline 2012 & 0.74 (0.66 to 0.83$)$ & & $0.60(0.51$ to 0.71$)$ & \\
\hline 2017 & 0.72 (0.64 to 0.80$)$ & & 0.57 (0.49 to 0.66$)$ & \\
\hline Age group, years & & $<0.001$ & & $<0.001$ \\
\hline $15-19$ & 1.07 (0.67 to 1.71$)$ & & - & \\
\hline $20-29$ & 1 & & - & \\
\hline $30-39$ & 1.05 (0.77 to 1.44$)$ & & - & \\
\hline $40-49$ & 1.32 (0.99 to 1.75$)$ & & - & \\
\hline $50-64$ & 2.27 (1.74 to 2.96$)$ & & - & \\
\hline $65-75$ & 6.26 (4.78 to 8.20$)$ & & 1 & \\
\hline$>75$ & $12.94(9.81 .17 .08)$ & & 2.04 (1.82 to 2.30$)$ & $<0.001$ \\
\hline Sex & & 0.66 & & 0.37 \\
\hline Male & 1 & & 1 & \\
\hline Female & 0.97 (0.88 to 1.08$)$ & & $1.06(0.93$ to 1.21$)$ & \\
\hline Pregnancy & & 0.67 & & - \\
\hline Yes & 0.91 (0.56 to 1.70$)$ & & - & \\
\hline No & 1 & & - & \\
\hline BMI group & & 0.87 & & 0.93 \\
\hline Underweight & 1 & & 1 & \\
\hline Normal & 0.97 (0.74 to 1.28$)$ & & $0.88(0.58$ to 1.34$)$ & \\
\hline Overweight & $0.94(0.72$ to 1.25$)$ & & 0.89 (0.59 to 1.36$)$ & \\
\hline Obese & 0.99 (0.74 to 1.32$)$ & & 0.91 (0.58 to 1.41$)$ & \\
\hline Language region & & $<0.001$ & & 0.01 \\
\hline German-speaking & 1 & & 1 & \\
\hline French-speaking & $1.31(1.20$ to 1.44$)$ & & $1.22(1.07$ to 1.38$)$ & \\
\hline Italian-speaking & 0.95 (0.82 to 1.12$)$ & & 1.05 (0.86 to 1.29$)$ & \\
\hline Setting & & $<0.001$ & & 0.02 \\
\hline Urban & $1.24(1.12-1.38)$ & & $1.19(1.03-1.37)$ & \\
\hline Rural & 1 & & 1 & \\
\hline Citizenship & & 0.80 & & 0.20 \\
\hline Swiss & 1 & & 1 & \\
\hline Non-Swiss & $0.98(0.85$ to 1.13$)$ & & 0.87 (0.70 to 1.08$)$ & \\
\hline Education level & & $<0.001$ & & 0.06 \\
\hline Primary & 1 & & 1 & \\
\hline Apprenticeship & 1.00 (0.88 to 1.14$)$ & & 1.05 (0.89 to 1.23$)$ & \\
\hline Secondary & $1.11(0.93$ to 1.31$)$ & & 1.14 (0.91 to 1.43$)$ & \\
\hline Tertiary & 1.26 (1.09 to 1.46$)$ & & 1.26 (1.04 to 1.53$)$ & \\
\hline Smoking & & $<0.001$ & & 0.009 \\
\hline Never smoked & 1 & & 1 & \\
\hline Former smoker & 1.17 (1.05 to 1.28$)$ & & 1.22 (1.07 to 1.39$)$ & \\
\hline Current smoker & 0.91 (0.81 to 1.02$)$ & & 1.01 (0.85 to 1.20$)$ & \\
\hline Self-reported health status & & $<0.001$ & & $<0.001$ \\
\hline
\end{tabular}


Table 3 Continued

\begin{tabular}{|c|c|c|c|c|}
\hline \multirow[b]{2}{*}{ Characteristic } & \multicolumn{2}{|l|}{ All } & \multicolumn{2}{|l|}{$\geq 65$ years old } \\
\hline & Adjusted OR (95\% Cl) & $P$ value & Adjusted OR $(95 \% \mathrm{Cl})$ & $P$ value \\
\hline Very good & 1 & & 1 & \\
\hline Good & $1.16(1.03$ to 1.31$)$ & & 1.30 (1.10 to 1.53$)$ & \\
\hline Moderate & 1.56 (1.36 to 1.80$)$ & & 1.65 (1.36 to 2.01$)$ & \\
\hline Bad & $2.13(1.70$ to 2.65$)$ & & 2.03 (1.46 to 2.81$)$ & \\
\hline Very bad & 2.07 (1.26 to 3.40$)$ & & 1.79 (0.92 to 3.45$)$ & \\
\hline Hospital stay insurance & & $<0.001$ & & $<0.001$ \\
\hline Basic & 1 & & 1 & \\
\hline Semiprivate & $1.43(1.30$ to 1.59$)$ & & $1.42(1.24$ to 1.63$)$ & \\
\hline Private & 1.78 (1.56 to 2.03$)$ & & $1.86(1.56$ to 2.21$)$ & \\
\hline Other & 1.28 (0.86 to 1.92$)$ & & 0.89 (0.50 to 1.58$)$ & \\
\hline Use of any complementary medicine therapy* & & $<0.001$ & & $<0.001$ \\
\hline Yes & $0.72(0.66$ to 0.80$)$ & & $0.65(0.57$ to 0.75$)$ & \\
\hline No & 1 & & 1 & \\
\hline \multicolumn{5}{|l|}{ Chronic diseases $\dagger$} \\
\hline Any chronic disease & 1.84 (1.69 to 2.09$)$ & $<0.001$ & 1.68 (1.51 to 1.88$)$ & $<0.001$ \\
\hline Diabetes & 1.54 (1.33 to 1.77$)$ & $<0.001$ & $1.46(1.23$ to 1.73$)$ & $<0.001$ \\
\hline Lung disease & 1.81 (1.46 to 2.26$)$ & $<0.001$ & 1.59 (1.16 to 2.18$)$ & 0.004 \\
\hline Cerebrovascular disease & 1.12 (0.74 to 1.69$)$ & 0.59 & 0.91 (0.58 to 1.42$)$ & 0.68 \\
\hline Cardiovascular disease & 1.50 (1.34 to 1.68$)$ & $<0.001$ & 1.44 (1.26 to 1.64$)$ & $<0.001$ \\
\hline Cancer & $1.22(0.97$ to 1.55$)$ & 0.09 & 1.05 (0.80 to 1.38$)$ & 0.12 \\
\hline Healthcare worker’‡ & 1.92 (1.64 to 2.24$)$ & $<0.001$ & - & - \\
\hline
\end{tabular}

Model adjusted for all variables included in the table. Unadjusted ORs are shown in online supplemental table 2.

${ }^{*}$ Current pregnancy in women $15-49$ years.

†Use of any alternative therapy in the past 12 months (including acupuncture, traditional Chinese medicine, homeopathy, and osteopathy). $\ddagger$ Any current chronic disease versus no chronic disease (reference); lung diseases: asthma bronchiale, chronic bronchitis and emphysema versus no lung disease (reference); diabetes: use of any diabetic drug versus no diabetes (reference); cardiovascular disease: use of any heart medication versus no cardiovascular disease (reference); all other diseases: self-reported disease versus no disease (reference).

$\S$ Estimates from separate models which included the variable 'any chronic disease' instead of specific chronic diseases.

I|Any profession in the healthcare system (in the 2007 survey, the veterinary professions were also included in this category) versus any other profession (reference).

BMI, body mass index.

information about the safety of vaccines might have increased the vaccine hesitancy and reduced the coverage of some vaccines. ${ }^{13}$

The decline in coverage and an increase in vaccine hesitancy is of general concern. In the last years, several countries of the WHO European Region including Switzerland, had large outbreaks of vaccine-preventable diseases, including measles, rubella and influenza. Switzerland and other countries identified steps to improve vaccination coverage for vaccine-preventable infectious diseases. ${ }^{1415}$ The relationship between vaccination uptake, knowledge, attitudes and awareness is complex. ${ }^{16}$ Reasons for people not getting vaccinated against influenza include underestimation of disease severity, fear of side effects and the cost of vaccines. ${ }^{17-19}$ Often people are unaware that they should receive the vaccination. ${ }^{17}$ For the seasonal influenza, the varying efficiency ranging from $30 \%$ to $60 \%$ depending on the season could play a role in the reduced coverage over time. ${ }^{20}{ }^{21}$ However, mathematical models of influenza and vaccination showed that the health burden associated with influenza is more sensitive to changes in vaccination coverage than to changes in vaccine efficacy. ${ }^{21}$ Of note, the coverage of measles vaccination increased to almost $90 \%$ in young adults in Switzerland, probably due to the campaigns and a national measles strategy. ${ }^{22}$ The experience with measles could serve as a model for public health actions influenza.

The advent of the novel COVID-19 SARS-CoV-2 has profoundly changed everyday life in Switzerland and elsewhere. It is unclear how the COVID-19 pandemic will affect attitudes toward vaccines. The director of the US Centers for Disease Control has warned that a possible second wave of COVID-19 could be worse than the first. ${ }^{23}$ This has already been seen in the 'Spanish influenza' pandemic of 1918/1919. The Spanish influenza affected Switzerland in two waves. The first one occurred in July 
1918, the second, more severe one, in October-November $1918 .{ }^{24}$ However, even in the absence of a second wave, a resurgence of COVID-19 that coincides with the start of the influenza season could significantly stress healthcare systems. An effective and safe vaccine against COVID-19 is unlikely to become widely available in 2020 . Therefore, low influenza vaccination rates at around half the $75 \%$ coverage recommended for high-risk groups constitute a hazard that merits prompt, focused attention by public health authorities.

A concerted effort to increase influenza vaccination coverage in 2020/2021, when the COVID-19 pandemic to continue to pose a threat to the public's health, is urgently needed. Influenza vaccination prevents deaths, morbidity, hospital admissions and other adverse health outcomes, in target populations such as older people, chronically ill people ${ }^{25-30}$ and also children ${ }^{31}$ and pregnant women. ${ }^{32}$ The continued promotion of infection control measures such as avoiding close contact with sick people, covering one's nose and mouth while coughing or sneezing, social distancing and hand hygiene will contribute to reducing the spread of both influenza and COVID-19. ${ }^{3}$

Our study has several limitations. Influenza vaccination status is self-reported in the Swiss Health Survey, and the reliability of the data unclear. For example, vaccination coverage could be lower if social desirability bias led to an overestimation of uptake. Conversely, incomplete recall of vaccinations could bias coverage downwards. Individuals younger than 15 years are excluded from the survey, but coverage in this age group might be even lower than in the 15-19years old. A strength of our analysis is the fact that the survey is a nationwide and representative, and repeated every 5 years using the same methodology. Also, the analyses were weighted and adjusted for a range of potential confounders, which did not substantially change the results.

In conclusion, we need to increase influenza vaccination uptake, particularly in the elderly and chronically ill, who are also the risk groups most heavily affected by COVID-19. These efforts should include classic information campaigns, but novel approaches using social media should also be considered. ${ }^{33}{ }^{34}$ Recommendations by healthcare professionals are essential to improve influenza vaccination coverage, such as client reminder/recall and standing orders. ${ }^{35}$ The preparation of influenza season 2020/2021 must start now to address the double burden of COVID-19 and seasonal influenza.

\section{Patient and public involvement}

The Swiss Health Survey is a nationwide, representative survey that is repeated every 5 years using the same methodology. The survey is conducted by the SFSO on behalf of the Swiss Government. The content of the survey is based on a holistic and dynamic health framework and contains questions on essential topics for the public and politics. The wording of the questions is regularly harmonised with the statistical offices of other countries in Europe.

\section{Twitter Matthias Egger @eggersnsf}

Acknowledgements We thank the Swiss Federal Statistical Office for providing the data of the Swiss Health Survey 2007 to 2017, and the people who participated in the surveys.

Contributors Conception and design: LF, MZ, ME. Data analysis: KZ, LF, CB, MZ. KZ, $L F, M E$ wrote the first draft of the paper and revised it based on comments from all authors. All authors reviewed and approved the final version of the manuscript.

Funding There was no specific funding for this project. ME was supported by special project funding (grant 17481) from the Swiss National Science Foundation.

Competing interests None declared.

Patient consent for publication Not required.

Ethics approval Data were collected anonymised and ethical approval was not required but we obtained permission to analyse and publish the data through a contract with the SFSO (Ref. 624.110-1).

Provenance and peer review Not commissioned; externally peer reviewed.

Data availability statement Data may be obtained from a third party and are not publicly available. Data may be obtained upon request from the Swiss Federal Statistical Office (SFSO).

Supplemental material This content has been supplied by the author(s). It has not been vetted by BMJ Publishing Group Limited (BMJ) and may not have been peer-reviewed. Any opinions or recommendations discussed are solely those of the author(s) and are not endorsed by BMJ. BMJ disclaims all liability and responsibility arising from any reliance placed on the content. Where the content includes any translated material, BMJ does not warrant the accuracy and reliability of the translations (including but not limited to local regulations, clinical guidelines, terminology, drug names and drug dosages), and is not responsible for any error and/or omissions arising from translation and adaptation or otherwise.

Open access This is an open access article distributed in accordance with the Creative Commons Attribution Non Commercial (CC BY-NC 4.0) license, which permits others to distribute, remix, adapt, build upon this work non-commercially, and license their derivative works on different terms, provided the original work is properly cited, appropriate credit is given, any changes made indicated, and the use is non-commercial. See: http://creativecommons.org/licenses/by-nc/4.0/.

\section{ORCID iDs}

Kathrin Zürcher http://orcid.org/0000-0002-7915-3194

Marcel Zwahlen http://orcid.org/0000-0002-6772-6346

Claudia Berlin http://orcid.org/0000-0003-3505-348X

Matthias Egger http://orcid.org/0000-0001-7462-5132

Lukas Fenner http://orcid.org/0000-0003-3309-4835

\section{REFERENCES}

1 Nicholson KG, Wood JM, Zambon M. Influenza. Lancet 2003;362:1733-45

2 Fauci AS, Touchette NA, Folkers GK. Emerging infectious diseases: a 10-year perspective from the National Institute of allergy and infectious diseases. Emerg Infect Dis 2005;11:519-25.

3 Federal Office of Public Health. National influenza vaccination website, 2020. Available: https://www.vaccinateagainsttheflu.ch/enus/the-flu/how-dangerous-is-the-flu.html

4 Del Rio C, Malani PN. COVID-19-new insights on a rapidly changing epidemic. JAMA 2020;323:1339.

5 Thanh Le T, Andreadakis Z, Kumar A, et al. The COVID-19 vaccine development landscape. Nat Rev Drug Discov 2020;19:305-6.

6 World Health Organization ROfE. Evaluation of seasonal influenza vaccination policies and coverage in the WHO European region, 2020. Available: http://www.euro.who.int/_data/assets/pdf_file/ 0003/241644/Evaluation-of-seasonal-influenza-vaccination-policiesand-coverage-in-the-WHO-European-Region.pdf

7 Federal Office of Public Health. National influenza vaccination website: vaccine recommendations. Available: https://wwwvaccinateagainstthefluch/en-us/vaccination/ impfempfehlungenhtml

8 Zürcher K, Zwahlen M, Berlin C, et al. Trends in influenza vaccination uptake in Switzerland: Swiss health survey 2007 and 2012. Swiss Med Wkly 2019;149:w14705.

9 Swiss Federal Statistical Office. Schweizerische Gesundheitsbefragung, 2020. Available: https://www.bfs.admin.ch/ bfs/de/home/statistiken/gesundheit/erhebungen/sgb.html 
10 Health FOoP. Health insurance, 2020. Available: https://www.bag. admin.ch/bag/en/home/versicherungen/krankenversicherung.html

11 Jorgensen P, Mereckiene J, Cotter S, et al. How close are countries of the WHO European Region to achieving the goal of vaccinating $75 \%$ of key risk groups against influenza? Results from national surveys on seasonal influenza vaccination programmes, 2008/2009 to $2014 / 2015$. Vaccine 2018;36:442-52.

12 Andre FE, Booy R, Bock HL, et al. Vaccination greatly reduces disease, disability, death and inequity worldwide. Bull World Health Organ 2008;86:140-6.

13 Folb PI, Bernatowska E, Chen R, et al. A global perspective on vaccine safety and public health: the global Advisory Committee on vaccine safety. Am J Public Health 2004;94:1926-31.

14 The Lancet. Addressing decreasing vaccine coverage in the EU. Lancet 2018;391:1638.

15 European Union. EU manifesto on influenza vaccination. our response to the burden of influenza in Europe, 2020. Available: www. eufightingflu.com

16 Larson HJ, Jarrett C, Eckersberger E, et al. Understanding vaccine hesitancy around vaccines and vaccination from a global perspective: a systematic review of published literature, 2007-2012. Vaccine 2014;32:2150-9.

17 Casalino E, Ghazali A, Bouzid D, et al. Patient's behaviors and missed opportunities for vaccination against seasonal epidemic influenza and evaluation of their impact on patient's influenza vaccine uptake. PLoS One 2018;13:e0193029.

18 Wendlandt R, Cowling BJ, Chen Y. Knowledge, attitudes and practices related to the influenza virus and vaccine among older adults in eastern China. Vaccine 2018;36:2673-82.

19 Wheelock A, Thomson A, Sevdalis N. Social and psychological factors underlying adult vaccination behavior: lessons from seasonal influenza vaccination in the US and the UK. Expert Rev Vaccines 2013;12:893-901.

20 Sullivan SG, Chilver MB, Carville KS, et al. Low interim influenza vaccine effectiveness, Australia, 1 May to 24 September 2017. Euro Surveill 2017;22.

21 Sah P, Medlock J, Fitzpatrick MC, et al. Optimizing the impact of low efficacy influenza vaccines. Proceedings of the National Academy of Sciences of the United States of America, 2018.

22 Altpeter E, Wymann MN, Richard JL, et al. Marked increase in measles vaccination coverage among young adults in Switzerland: a campaign or cohort effect? Int J Public Health 2018.
23 Sun Lena $\mathrm{H}$. CDC director warns second wave of coronavirus is likely to be even more devastating, 2020. Available: https://www. washingtonpost.com/health/2020/04/21/coronavirus-secondwavecdcdirector/

24 Ammon CE. Spanish flu epidemic in 1918 in Geneva, Switzerland. Euro Surveill 2002;7:190-2.

25 Talbot HK, Zhu Y, Chen Q, et al. Effectiveness of influenza vaccine for preventing laboratory-confirmed influenza hospitalizations in adults, 2011-2012 influenza season. Clin Infect Dis 2013;56:1774-7.

26 Pereira M, Williams S, Restrick L, et al. Healthcare worker influenza vaccination and sickness absence - an ecological study. Clin Med 2017;17:484-9.

27 Phrommintikul A, Kuanprasert S, Wongcharoen W, et al. Influenza vaccination reduces cardiovascular events in patients with acute coronary syndrome. Eur Heart J 2011;32:1730-5.

28 Colquhoun AJ, Nicholson KG, Botha JL, et al. Effectiveness of influenza vaccine in reducing hospital admissions in people with diabetes. Epidemiol Infect 1997;119:335-41.

29 Liu W-C, Lin C-S, Yeh C-C, et al. Effect of influenza vaccination against postoperative pneumonia and mortality for geriatric patients receiving major surgery: a nationwide matched study. J Infect Dis 2018;217:816-26.

30 Arriola CS, Anderson EJ, Baumbach J, et al. Does influenza vaccination modify influenza severity? data on older adults hospitalized with influenza during the 2012-2013 season in the United States. J Infect Dis 2015;212:1200-8.

31 Ferdinands JM, Olsho LEW, Agan AA, et al. Effectiveness of influenza vaccine against life-threatening RT-PCR-confirmed influenza illness in US children, 2010-2012. J Infect Dis 2014;210:674-83.

32 Mosby LG, Rasmussen SA, Jamieson DJ. 2009 pandemic influenza A ( $\mathrm{H} 1 \mathrm{~N} 1)$ in pregnancy: a systematic review of the literature. $A m \mathrm{~J}$ Obstet Gynecol 2011;205:10-18.

33 NHS Foundation Trust. The flu bee game web APP, 2020. Available: http://www.focusgames.com/case_studies/Flu\%20Bee\%20-\% 20Case\%20Study\%202018.pdf

34 Glanz JM, Wagner NM, Narwaney KJ, et al. Web-based social media intervention to increase vaccine acceptance: a randomized controlled trial. Pediatrics 2017;140 doi:10.1542/peds.2017-1117

35 Lu P-J, Srivastav A, Amaya A, et al. Association of provider recommendation and offer and influenza vaccination among adults aged $\geq 18$ years - United States. Vaccine 2018;36:890-8. 